\title{
Isothermal kinetics of carbothermic reduction of ilmenite concentrate with the addition of sodium carbonate
}

\author{
Xiaodong $\mathrm{Lv}^{1}$, Dan Chen ${ }^{1}$, Yuntao Xin ${ }^{1}$, Jie Dang ${ }^{2}$, Wei $\mathrm{Lv}^{1}$, and Xuewei $\mathrm{Lv}^{1}$ \\ ${ }^{1}$ Chongqing University \\ ${ }^{2}$ Affiliation not available
}

October 31, 2020

\begin{abstract}
The isothermal kinetics of carbothermic reduction of low grade ilmenite concentrate with the addition of sodium carbonate which was regarded as a novel process to obtain high quality UGS slag used for chlorination process through the semi-molten states was studied. The results showed that the addition of $\mathrm{Na} 2 \mathrm{CO} 3$ can reduce the start temperature of the reaction and promote the reduction, which is benefit to improve the reaction kinetic by enhancing the carbon gasification reaction. The metal iron produced during the reaction was more likely to migrate and grow with the formation of the molten phase. With the increase of sodium carbonate, the reduction process of ilmenite concentrate is gradually changed from controlled by interfacial chemical reaction to controlled by diffusion. When the amount of sodium carbonate was $0 \%, 3 \%$ and $6 \%$, the apparent activation energies were $105.01,112.07$ and $123.48 \mathrm{~kJ} / \mathrm{mol}$, respectively.
\end{abstract}

\section{Hosted file}

manuscript.pdf available at https://authorea.com/users/371922/articles/490105-isothermalkinetics-of-carbothermic-reduction-of-ilmenite-concentrate-with-the-addition-of-sodiumcarbonate 

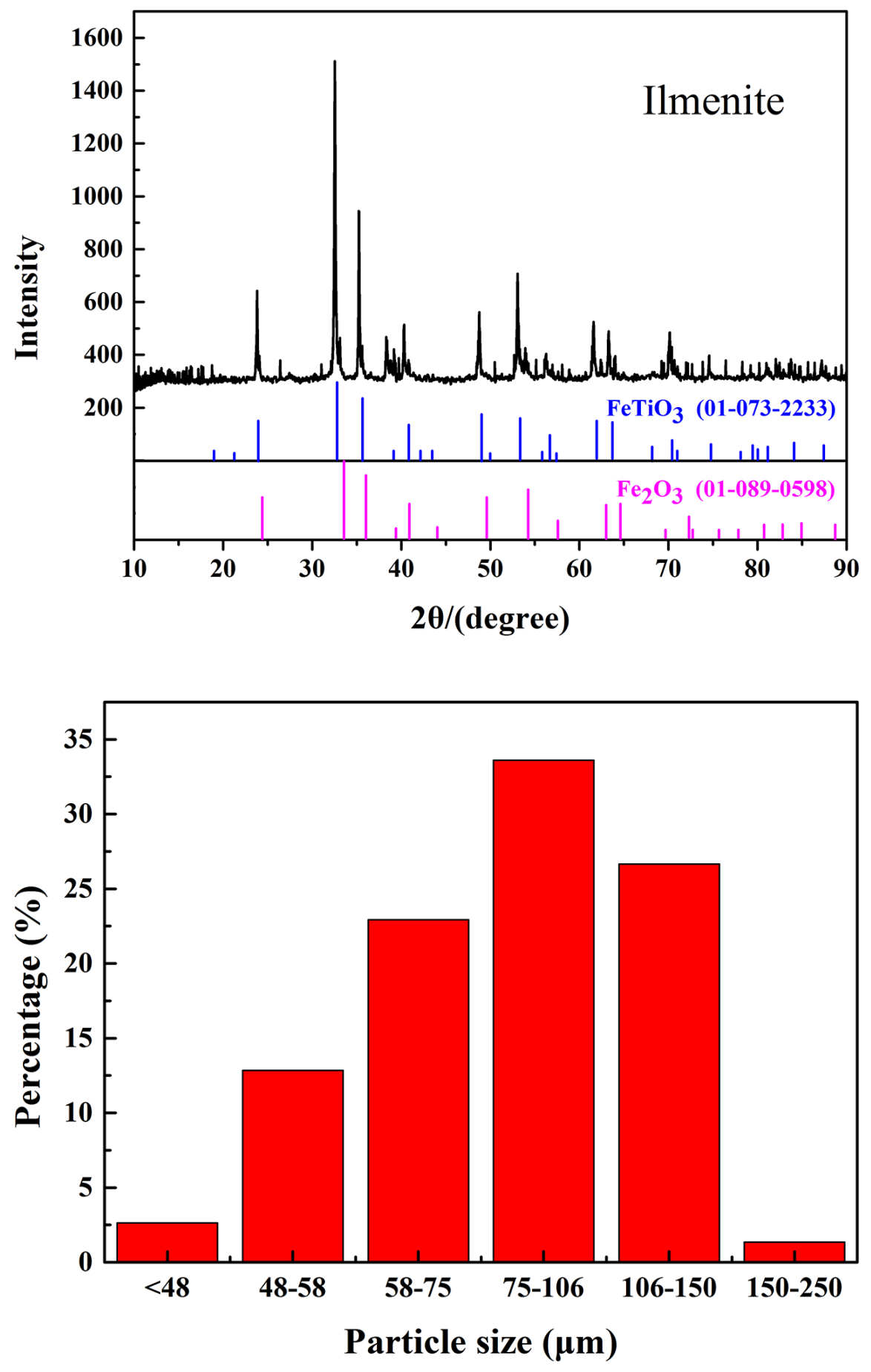




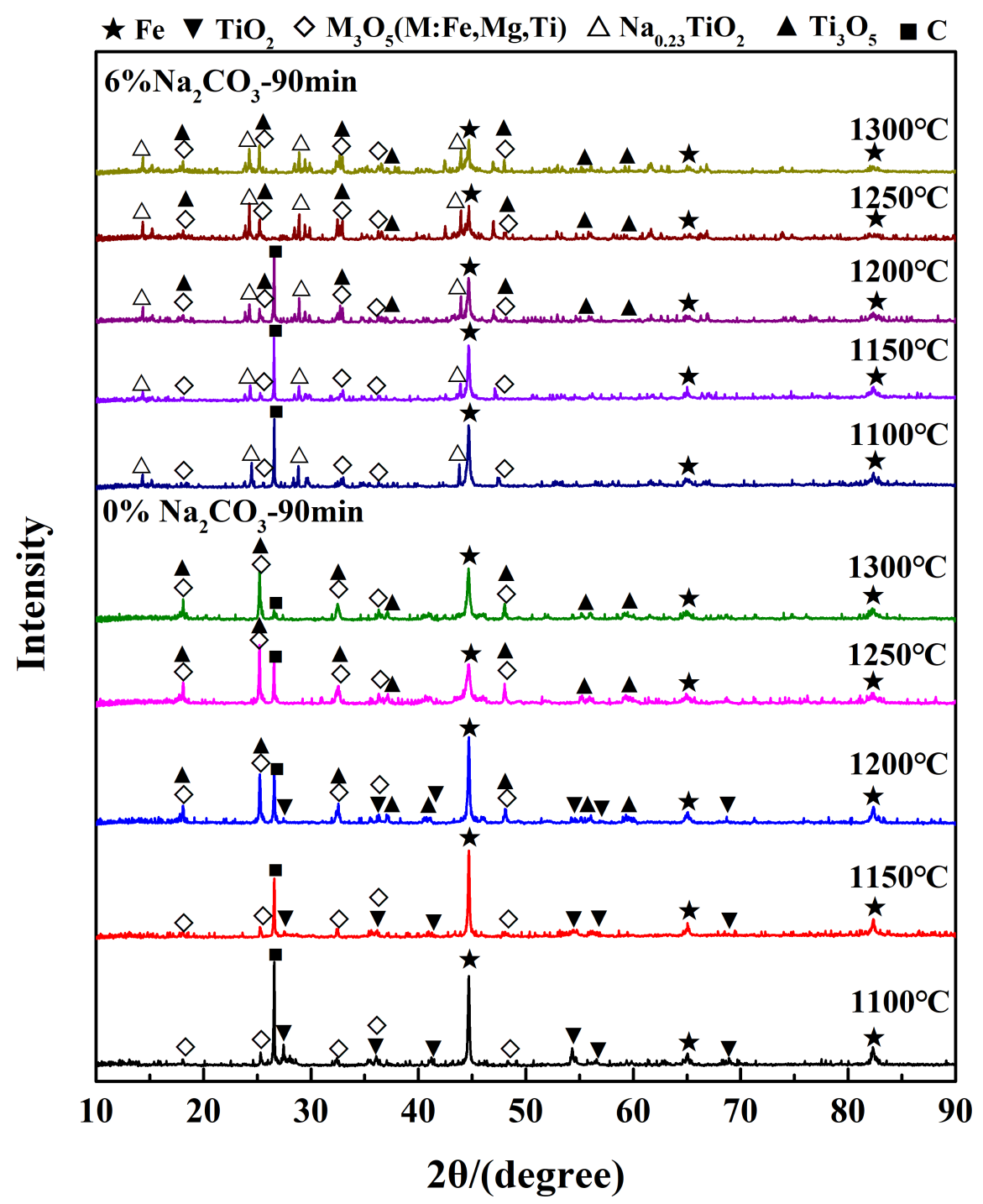



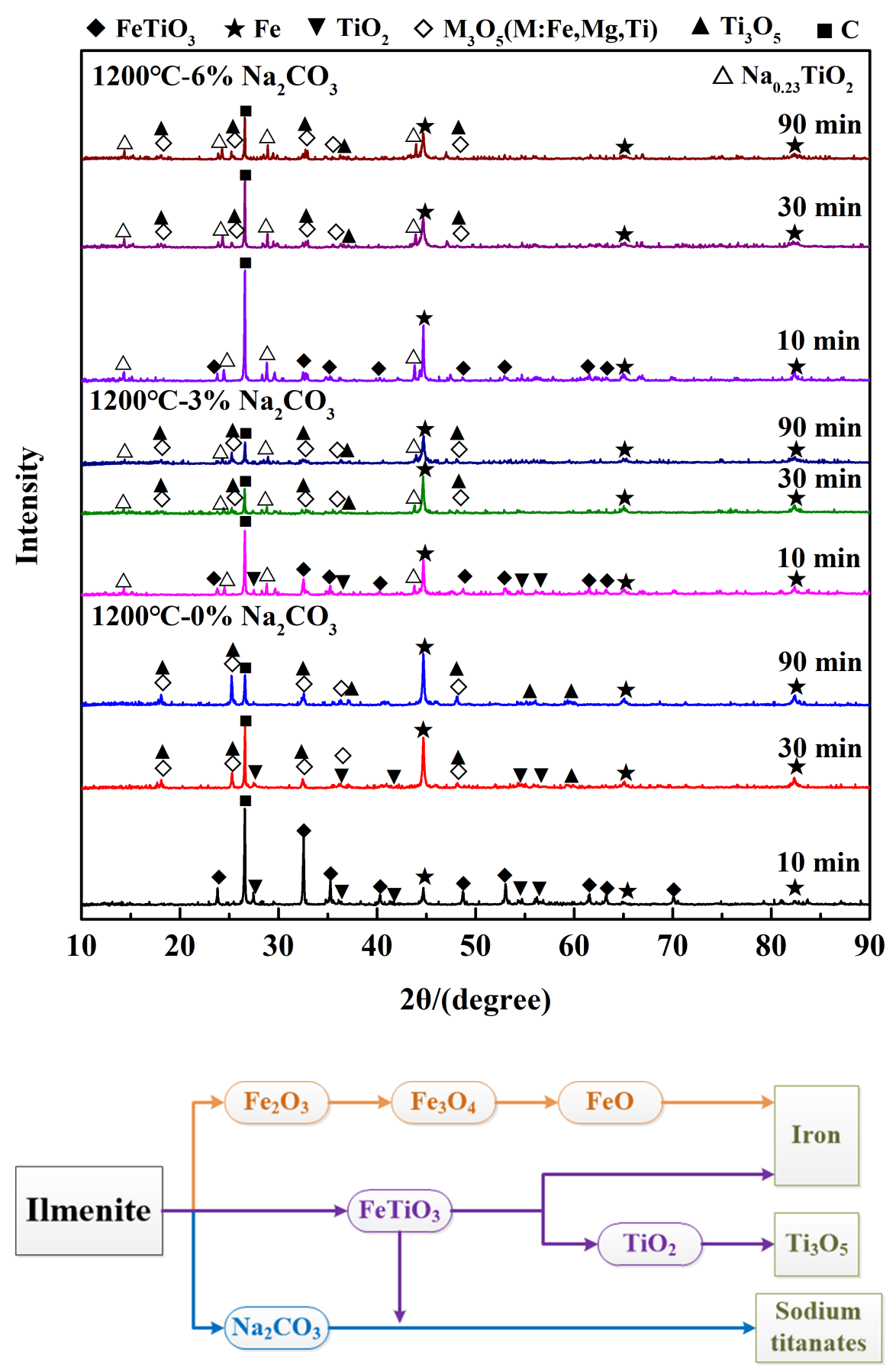

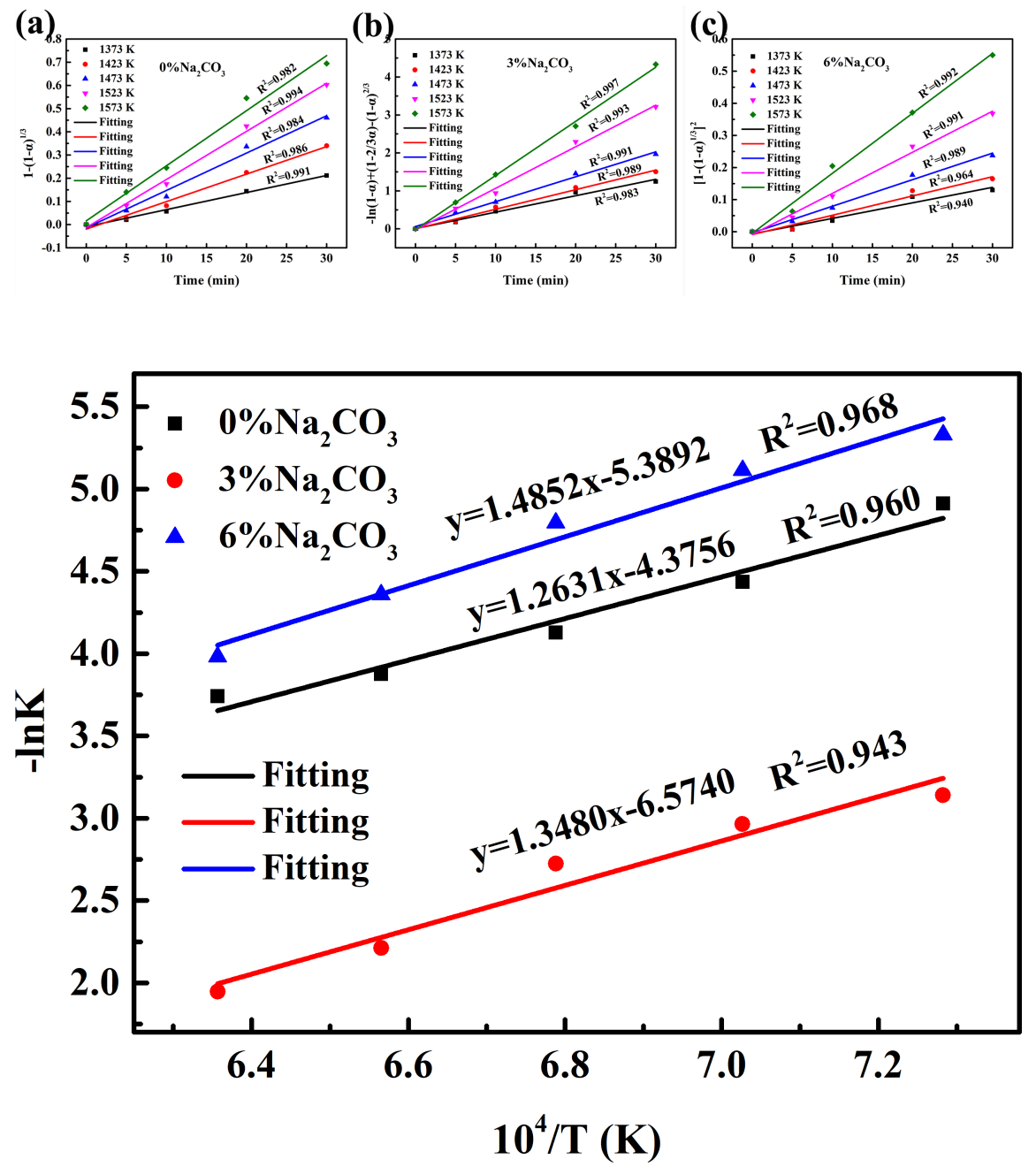

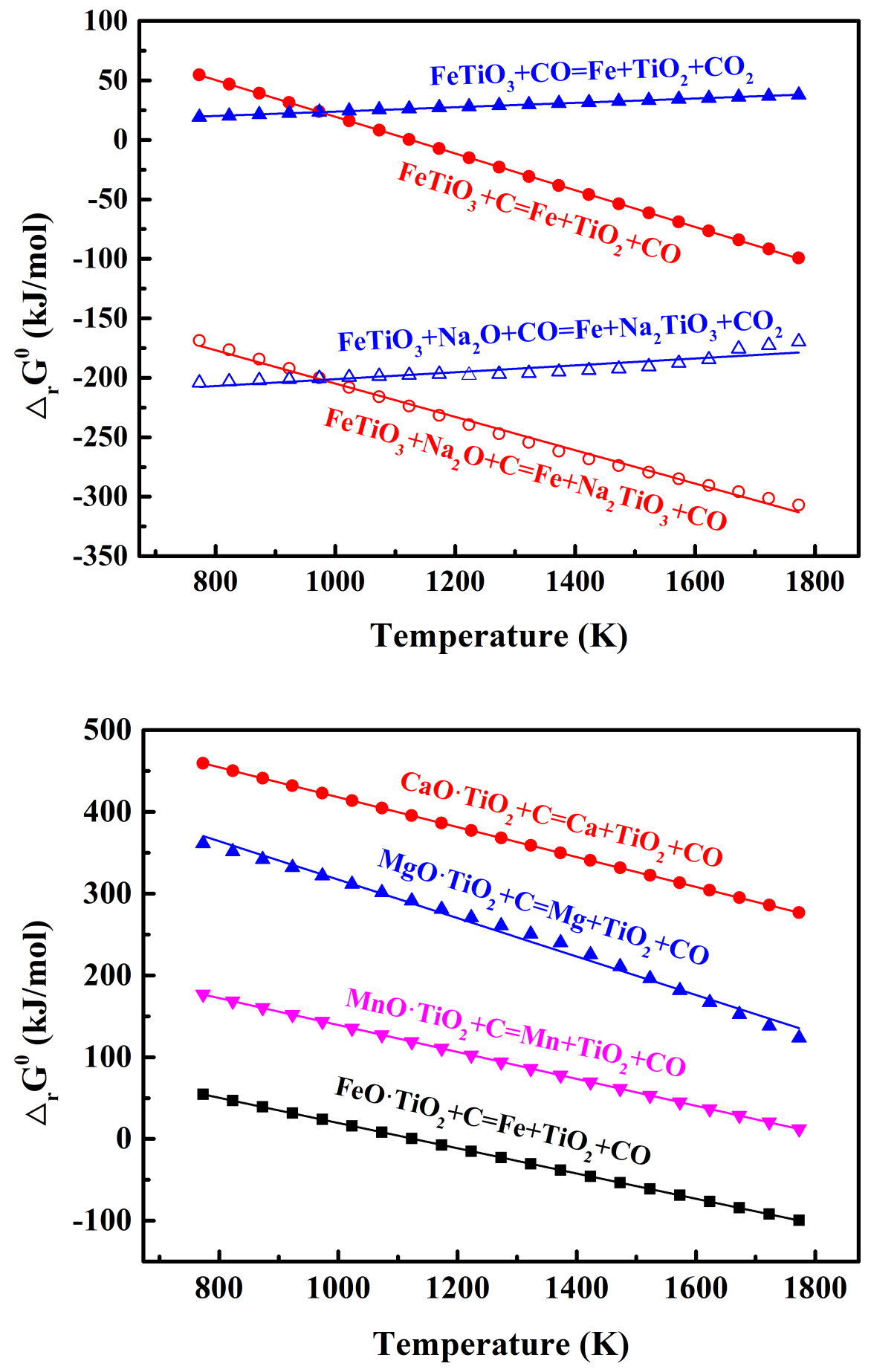

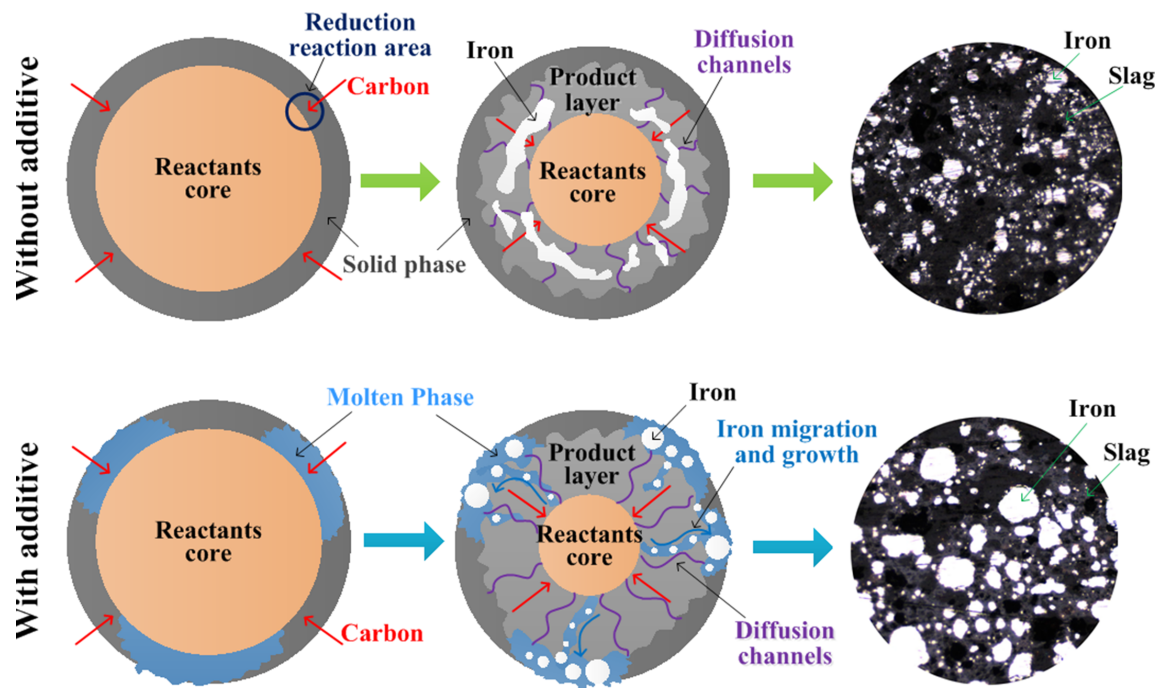

\section{Hosted file}

Table.pdf available at https://authorea.com/users/371922/articles/490105-isothermal-kineticsof-carbothermic-reduction-of-ilmenite-concentrate-with-the-addition-of-sodium-carbonate 